\title{
O papel do conhecimento acerca da estrutura do texto na escrita de histórias por crianças
}

\section{The role of knowledge about the structure of the text in the writing of stories by children}

\author{
Alina Galvão Spinillo* \\ Kátia Leal Reis de Melo**
}

\begin{abstract}
RESUMO
O estudo investigou se ao tomar consciência do esquema prototípico de histórias as crianças seriam capazes de aplicá-lo a suas produções, passando a escrever histórias elaboradas. Estudantes do $2^{\circ}$ ano do ensino fundamental realizaram um pré-teste e um pós-teste que consistiam na escrita de uma história original. Após o pré-teste foram divididos em um Grupo Experimental e um Grupo Controle. As crianças do Grupo Experimental participaram de uma intervenção em que as propriedades constitutivas de histórias eram explicitadas. As histórias escritas nas duas ocasiões de testagem foram analisadas em função da estrutura narrativa apresentada e dos recursos coesivos empregados. Observou-se um impacto positivo da intervenção sobre a escrita de histórias coesas e elaboradas. Os dados indicam haver relações entre consciência metatextual e desenvolvimento da produção textual, sendo discutidas implicações educacionais para o ensino da escrita de textos no início da escolarização básica.
\end{abstract}

Palavras-chave: Estrutura textual. Recursos coesivos. Escrita de histórias. Crianças.

* Universidade Federal de Pernambuco. Pós-Graduação em Psicologia Cognitiva. E-mail: alinaspinillo@hotmail.com. ORCID: https://orcid.org/0000-0002-6113-4454

** Universidade Federal de Pernambuco. Centro de Educação. E-mail: katiamelo@hotmail. com. ORCID: https://orcid.org/0000-0001-5087-4695 


\begin{abstract}
The study investigated whether once children have become aware of the prototypical schema for stories, they are able to apply it to their productions, and then produce elaborate stories. Children attending the $2^{\text {nd }}$ year of elementary school did a pre-test and a post-test, both involving writing an original story. After the pre-test, they were divided into an Experimental Group and a Control Group. Children in the Experimental Group received an intervention in which they were explicitly taught about the characteristics of stories. The stories written in both testing occasions were analysed according to their narrative structure and the use of cohesive devices. The intervention had a positive impact and resulted in the production of cohesive and elaborate stories. The data indicate relationships between metatextual awareness and the development of textual production. Educational implications for the teaching of writing texts at the beginning of elementary school are discussed.
\end{abstract}

Keywords: Textual structure. Cohesive devices. Written stories. Children.

\title{
Introdução
}

Pontecorvo, Orsolini e Resnick (1996) afirmam que o texto é a essência da linguagem, de maneira que a competência linguística dos indivíduos está associada à capacidade de compreender e produzir textos. A escrita de textos, em particular, depende de diversos conhecimentos como o domínio do sistema de escrita, das regras sintáticas e ortográficas da língua e conhecimentos sobre suas características estruturais. Esse último aspecto é tratado nesta investigação em relação a um tipo de texto familiar às crianças: a história.

A escrita de histórias é usualmente examinada a partir de fatores como a idade/escolaridade e as situações de produção, como é o caso da pesquisa de Rego (1986). A autora analisou o desenvolvimento de um esquema narrativo em crianças, propondo categorias de produção que variam desde histórias que se limitam à introdução da cena e dos personagens, até histórias completas com um esquema narrativo elaborado, com as convenções linguísticas típicas desse tipo de texto. Fayol (1991) também verificou uma progressão: inicialmente as narrativas consistiam em eventos únicos ou justapostos, passando a apresentar vários eventos articulados em sequências causais.

Progressão também foi encontrada em relação ao uso de coesivos, tanto em histórias orais (SPINILLO, 1996) como escritas (FAYOL; MOUCHON, 1997), uma vez que os recursos coesivos eram mais frequentes e variados quando a ca- 
deia narrativa era mais complexa e organizada, incluindo uma situação-problema e sua resolução. No estudo de Fayol e Mouchon, a idade foi fator importante na emergência de cadeias narrativas elaboradas.

O efeito de diferentes situações de produção foi examinado por Lins e Silva e Spinillo (2000). Crianças de 7 a 10 anos escreveram histórias em quatro situações: produção livre, produção escrita após a produção oral, produção a partir de uma sequência de gravuras e a reprodução de uma história ouvida. O efeito da situação foi observado apenas entre as crianças mais novas, cujas histórias mais elaboradas eram aquelas reproduzidas e aquelas baseadas na sequência de gravuras. As histórias das crianças mais velhas apresentavam uma estrutura narrativa elaborada em todas as situações. Resultado semelhante foi encontrado por Pessoa, Correa e Spinillo (2010) em relação ao estabelecimento da coerência textual ao analisarem as histórias escritas por crianças do $2^{\circ}$ e $3^{\circ}$ ano do ensino fundamental em duas situações: escrita livre e reprodução de um conto infantil. Entre os alunos do $2^{\circ}$ ano, as histórias classificadas em níveis sofisticados de coerência eram aquelas escritas na situação de reprodução, enquanto as dos alunos do $3^{\circ}$ ano atingiam esses níveis em ambas as situações.

Tomados de forma conjunta, esses estudos evidenciam que as crianças em anos escolares iniciais tendem a produzir melhores histórias em condições em que há um apoio que sirva de modelo, seja ele um apoio linguístico (uma história a ser reproduzida) ou um apoio pictórico (sequência de gravuras). Nota-se, portanto, que a escrita de histórias é influenciada pelas situações de produção, havendo aquelas, como a reprodução, que favorecem a produção de textos coesos, coerentes e com uma estrutura e organização elaboradas.

Instruções acerca da estrutura do texto também têm um efeito positivo tanto em relação à escrita de textos expositivos (e.g., ENGLERT; STEWART; HIEBERT, 1988; REYNOLDS; PERIN, 2009; TAYLOR; BEACH, 1984) como narrativos (FITZGERALD; TEASLEY, 1986; PINHEIRO; BECKER, 2014; SINGER; BASHIR, 2004). Esses resultados foram obtidos a partir de programas de intervenção oferecidos a estudantes de 10 a 14 anos. Cabe perguntar se esse efeito positivo seria também observado na escrita de crianças mais jovens alunas dos anos iniciais do ensino fundamental. Esta possibilidade foi examinada por Ferreira e Spinillo (2003) em relação à produção oral de histórias.

Ferreira e Spinillo (2003) investigaram o papel de uma intervenção de natureza metatextual sobre a produção oral de histórias. Crianças com idades entre 7 e 8 anos, alunas do $2^{\circ}$ e $3^{\circ}$ ano do ensino fundamental foram divididas em dois grupos experimentais (um em cada ano escolar) e dois grupos controles (um em cada ano escolar). O pré-teste e o pós-teste consistiam na produção oral de uma história. A intervenção, fornecida individualmente apenas aos participantes dos grupos experimentais, se caracterizava por um conjunto de atividades que 
levavam a criança, de forma explícita e deliberada, a refletir sobre as propriedades constitutivas de histórias: sua estrutura típica (organização e partes constituintes) e convenções linguísticas. O mesmo padrão de resultados foi observado em relação aos dois anos escolares, mostrando que após a intervenção, as crianças dos grupos experimentais produziam histórias bem mais elaboradas do que antes da intervenção, o que não ocorria com os grupos controles em que as histórias tendiam a ser elementares nas duas ocasiões de testagem. Concluiu-se que a intervenção propiciou o desenvolvimento da produção oral de histórias. A partir dessa evidência, é importante saber se esse mesmo impacto seria observado na escrita de textos. Será que tomar consciência do esquema narrativo próprio de histórias (sua organização, elementos constituintes e convenções linguísticas) propiciaria a escrita de histórias elaboradas? Responder essa questão foi o objetivo da presente investigação que tanto consiste em uma replicação da pesquisa de Ferreira e Spinillo (2003) como, de forma adicional, analisa a coesão textual das produções escritas.

\section{Método}

\section{Participantes}

Quarenta e seis estudantes do $2^{\circ}$ ano do ensino fundamental de escolas particulares localizadas em bairro de classe média em Recife foram igualmente divididos em um Grupo Experimental (12 meninas e 11 meninos, média de idade: 7 anos e 4 meses) e um Grupo Controle (13 meninas e 10 meninos, média de idade: 7 anos e 3 meses). Segundo o Teste U de Mann Whitney, aplicado no pré-teste, os dois grupos apresentavam o mesmo nível de desempenho uma vez que produziam histórias incompletas com uma estrutura narrativa elementar. A participação das crianças foi autorizada pelos pais/responsáveis, após esclarecimentos sobre a pesquisa, de acordo com os termos do CEP da UFPE (Ref: 125/2005).

\section{Planejamento experimental e Procedimentos}

Todos os participantes realizaram um pré-teste e um pós-teste, com um período de 30 a 35 dias entre eles. Às crianças do Grupo Experimental foi proporcionada uma intervenção individual fora do horário escolar regular. 
O pré-teste consistiu na produção escrita de uma história original cujo tema era 'A grande aventura'. A instrução para a escrita individual do texto foi dada coletivamente em uma sala, disponibilizando-se folhas de papel pautado, lápis e borracha. O mesmo procedimento foi adotado no pós-teste, sendo as crianças solicitadas a escrever uma outra história acerca do mesmo tema que haviam escrito no pré-teste. O resultado no pré-teste foi utilizado na composição do Grupo Controle e do Grupo Experimental, tornando-os equivalentes quanto ao nível de produção escrita, como mencionado.

A intervenção, baseada em Ferreira e Spinillo (2003), teve por objetivo desenvolver o conhecimento das crianças sobre as características estruturais próprias de histórias. Três sessões individuais foram aplicadas em dias alternados, com aproximadamente 40 minutos de duração cada e com duas atividades apresentadas em uma ordem fixa, como descrito a seguir:

Sessão 1: As atividades consistiam em pintar em cores diferentes o início, o meio e o final de histórias escritas, sendo explicado que no início da história são apresentados a cena (local e tempo em que os eventos acontecem) e os personagens; o meio da história versa sobre o que acontece com os personagens, seus objetivos e obstáculos que enfrentam; e a parte final é o desfecho. Eram mencionadas as convenções linguísticas típicas de abertura e fechamento de história. Concluída a atividade, o texto era lido sem interrupções.

Sessão 2: À medida que uma história era lida, estabelecia-se uma correspondência entre suas partes e gravuras que estavam embaralhadas, tendo a criança que identificar as partes que correspondiam ao início, meio e final da história. Em seguida a examinadora lia o início, o meio ou o final de diversas histórias, pedindo que indicasse que parte era aquela. Após a identificação de todas as partes, a criança oralmente completava a história.

Sessão 3: Eram apresentadas cartelas relativas ao início, ao meio e ao final de diferentes histórias, tendo a criança que ordenar as cartelas de forma a montar histórias completas e coerentes. Uma vez montadas, as histórias eram lidas na íntegra e sem interrupções.

Alguns procedimentos comuns às sessões foram adotados: (i) para minimizar as possíveis dificuldades de leitura, a examinadora lia todo o material escrito juntamente com o participante; (ii) justificativas eram solicitadas sistematicamente frente às respostas e ações dos participantes; e (iii) as intervenções da examinadora consistiam em feedback, correções e explicações complementares às respostas apresentadas e ações realizadas. As atividades, de natureza metatextual, requeriam que a criança refletisse, de forma explícita e deliberada, sobre as propriedades de uma história: suas partes constituintes (do que tratam e localização prototípica no texto), como se articulam e suas convenções linguísticas. No diálogo mantido ao longo das sessões foi gradativamente inserida 
terminologia específica, tais como: personagem, situação-problema, desfecho, conclusão. As passagens a seguir ilustram alguns momentos da intervenção ${ }^{1}$ :

\section{Sessão 1:}

E - (lê uma história) Onde está o começo desta história? Mostra para mim primeiro. Depois você pinta. (C - Tá aqui.) E - Por que este é o começo da história? O que faz essa parte ser o começo? (C - Porque é a casa de Seu Zequinha.) $\mathrm{E}$ - Ah! Onde a história acontece, né? No começo a gente fica sabendo onde as coisas acontecem e quem são os personagens da história; quem são as pessoas e os animais que aparecem na história. Na história de Chapeuzinho Vermelho, por exemplo, tem a Chapeuzinho Vermelho, a avó dela e o Lobo Mau. E nessa história daqui? Quem são os personagens que aparecem logo no começo da história? (C - silêncio) E - Essa história é sobre quem? (C - Da cabra e Seu Zequinha.) E - E aí, no começo, fala também onde eles estão, né? Onde ele e a cabra dele moram. Tudo isso tem que vir no começo da história. (C - Então eu vou pintar de azul, né?).

\section{Sessão 2:}

Final de história: Então, o leão aprendeu a lição: nunca se deve enganar os outros. E todos os animais da floresta viveram felizes para sempre.

$\mathrm{E}$ - Que parte da história é essa? ( $\mathrm{C}$ - O final.) E - Muito bem! Como sabe que era o final? ( $\mathrm{C}$ - Porque diz que o leão aprendeu a lição.) $\mathrm{E}$ - Tá certo! Ai também diz que eles "viveram felizes para sempre". Este é o jeito de terminar a história, né? No final da história sempre diz como tudo termina, é a conclusão, o fechamento da história. E como seria o meio dessa história? $(\mathrm{C}-\mathrm{O}$ meio ia ser assim, ó: uma vez existia muitos animais que moravam na floresta.) $\mathrm{E}-$ Este era o começo da história e não o meio. ( $\mathrm{C}$ - Mas o meio é o começo, não é o final não.) E - É nada! Tem o começo que começa com 'Era uma vez, 'Foi um dia'. No começo a gente fica sabendo quem são os personagens, onde eles moram e onde a história acontece. Aí depois, a gente vai ter o meio da história. No meio a gente fica sabendo o que os personagens querem e os problemas que eles têm, as dificuldades que eles têm para conseguir o que eles querem. No meio também diz o que foi que aconteceu com os personagens, com as pessoas ou os animais que estão na história. Aí a gente fica sabendo sobre os problemas delas que elas têm que resolver para poder viver felizes para sempre no final da história. ( $\mathrm{C}$ - Um problema é isso, né? Então eu ia fazer assim: as crianças estavam na floresta debaixo de um coqueiro e aí teve um incêndio na floresta. Então, apareceu o leão e ele queria comer as crianças. Aí então, o leão

1 A letra $\mathrm{E}$ antecede a fala da examinadora e a letra $\mathrm{C}$ (em parênteses) a fala do participante. 
se queimou-se no fogo e aprendeu a lição.) E - A lição vem no final. Mas no meio era o fogo na floresta. O problema que eles tinham. $\mathrm{O}$ final poderia ser as crianças escapando do leão e do fogo. Que acha? Agora vamos completar a história toda. Temos o final (lê novamente). Aí você disse que o meio era o fogo na floresta e os animais tentando escapar. Esse era o problema que eles tinham que resolver. E o que eles queriam era escapar do fogo. (C - Tinha também o leão que queria comer eles.) E - Eita! Quase que esquecia dessa parte. Muito bem! Vamos lá. Os animais queriam fugir do fogo e do leão. Isso podia ser o meio da história. E como podia ser o final, quando a gente explica como tudo termina? (C - Então, eles correram muito e escaparam do fogo. E o leão, o leão se queimou-se no fogo e aprendeu a lição. Então os animais viveram felizes para sempre. O leão não.)

\section{Sessão 3:}

Meio de uma história: O menino, então, esperou que seus pais fossem dormir e começou a comer os chocolates. Comeu todos eles, não deixando nenhum para sua mãe. No dia seguinte ele acordou com uma dor de barriga muito forte.

E - Esta cartela que a gente leu, que parte da história é essa? Tu sabes? (C - É o final.) E - Por que você pensa assim? (C - Porque diz o que foi que o menino fez.) $\mathrm{E}-\mathrm{O}$ fim é quando a gente fica sabendo como foi que tudo terminou na história. Nessa parte aqui, a gente sabe como foi que terminou? (C - Eita! É o meio!) E - Você disse que era o final. Por que mudou de ideia? (C É o meio, a parte que diz pra gente sobre o problema.) E - Que mais? Explica melhor. ( $\mathrm{C}-\mathrm{O}$ começo é quando a gente fica sabendo de tudinho.) $\mathrm{E}-$ Tudinho como? (C - Quem tá na história: o menino e a mãe dele. Aí o meio conta o que aconteceu pra eles, que o menino foi guloso e comeu tudo. Isso é muito feio! Ele não dividiu com ninguém. É isso que mostrou, não foi?)

\section{Análise dos dados e resultados}

As histórias produzidas foram analisadas em função dos aspectos estruturais e dos elos de coesão empregados, uma vez que, conforme a linguística textual, essas instâncias se configuram como princípios da textualidade que são adotados pelo escritor competente.

Para caracterizar os aspectos estruturais de histórias, pesquisadores elaboraram modelos que descrevem seus elementos constituintes e sua organização prototípica denominada esquema de histórias. Apesar de variações (SPINILLO, 
2001), esses modelos incluem, de modo geral, uma introdução que apresenta os personagens e os contextos físico, temporal e social em que estão inseridos, suas metas, os eventos e reações a esses eventos, tentativas de resolução de situações-problema e uma conclusão. Esses componentes aparecem de forma organizada através de convenções linguísticas próprias. São esses princípios constitutivos que permitem avaliar a qualidade narrativa da história, como ocorre com as categorias de análise adotadas neste estudo.

A coesão se expressa na forma de marcas linguísticas presentes na superfície do texto, assegurando sua continuidade, sequência e articulação. Marcuschi (2008) ressalta duas grandes categorias de recursos coesivos: a conexão referencial e a sequencial, ambas analisadas nesta investigação. A coesão referencial é aquela em que um elemento faz remissão a outros elementos do texto, como os pronomes pessoais e demonstrativos. Tais elos, de natureza sintático-semântica, permitem a interpretação de um elemento no texto que é dependente de outro que o antecede ou que o segue. A coesão sequencial, por sua vez, se pauta na ligação e no encadeamento das proposições, e se realiza por elementos conectivos como as conjunções.

\section{As categorias em que as histórias escritas foram classificadas}

Cada história foi classificada em uma dentre quatro categorias baseadas em Ferreira e Spinillo (2003) a saber²:

Categoria I - produções que se limitam à introdução da cena e dos personagens, podendo haver a presença de marcadores linguísticos convencionais de início de história ('Era uma vez ...', "Foi um dia...”). Exemplo: "Era uma vez um garoto chamado Eduardo. Ele estava numa aventura. Estava numa aventura. Estava numa floresta e pensando em começar a aventura dele."

Categoria II - produções em que, além da introdução da cena e dos personagens, há uma ação que sugere o esboço de uma trama ou situação-problema. É possível identificar-se a presença de marcadores linguísticos convencionais de início de história, mas o desfecho está ausente. Exemplo: "Era uma vez uma menina clamada Emili que tinha 16 anos. Emili era bonita e educada. Mas um dia ela foi acampar na floresta. Ela viu tigre dente de sabre e o tigre seguiu Emili, e ai ela correu para o rio."

2 Nos exemplos, manteve-se a escrita dos participantes com os equívocos ortográficos, gramaticais e de pontuação que apresentavam. 
Categoria III - além dos elementos anteriores, a história possui desfecho com uma súbita resolução da situação-problema, sem que sejam explicitados os meios utilizados para tal. As produções podem apresentar marcadores linguísticos convencionais de início e final de história ('... e foram felizes para sempre'). Exemplo: "Era uma vez dois meninos que iam na casa fantasma, numa casa assombrada. E eles foram para lá. Quando eles chegaram lá eles viram um fantasma. E eles foram pegar o fantasma. Eles pegaram e voltaram para a casa deles. E foi uma grande aventura. Fim."

Categoria IV - histórias completas, com estrutura narrativa elaborada, em que o desfecho e a resolução da situação-problema são explicitados. Marcadores linguísticos convencionais de início e final de história estão geralmente presentes. Exemplo: "Num certo dia um menino chamado Marcos que tinha 15 anos. Ele morava em uma casa perto da floresta. Um dia ele convidou dois amigos, para acampar na floresta os amigos chamados Gabriel e Matheus com 15 anos. No dia seguinte eles foram pra floresta. Quando montaram o acampamento começou a chover. Quando parou a chuva, eles estavam perdidos na floresta. Começou a escurecer e eles resolveram pegar a lanterna e sair da cabana. Ai acharam uma bússula quebrada no chão. Eles levaram pra cabana e Gabriel conseguiu consertar a bússula. E Marcos lembrou a direção de casa e voltaram pra casa e eles ficaram felizes."

Dois juízes cegos e independentes analisaram cada história, obtendo-se $87 \%$ de concordância entre eles. Os casos de discordância foram desempatados por um terceiro juiz, também cego e independente.

Como mostra a Tabela 1, e confirmado pelo U de Mann Whitney, no pré-teste os grupos não diferiam, pois eram raras as histórias na Categoria I e na Categoria IV, havendo uma concentração na Categoria II $(52,2 \%)$.

TABELA 1 - PORCENTAGEM DE HISTÓRIAS EM CADA CATEGORIA DE PRODUÇÃO

\begin{tabular}{ccccc}
\hline & \multicolumn{2}{c}{ Grupo Controle } & \multicolumn{2}{c}{ Grupo Experimental } \\
\hline Categoria & $\begin{array}{c}\text { Pré-teste } \\
(\mathrm{n}=23)\end{array}$ & $\begin{array}{c}\text { Pós-teste } \\
(\mathrm{n}=23)\end{array}$ & $\begin{array}{c}\text { Pré-teste } \\
(\mathrm{n}=23)\end{array}$ & $\begin{array}{c}\text { Pós-teste } \\
(\mathrm{n}=23)\end{array}$ \\
\hline I & 4,3 & 0 & 13 & 0 \\
II & 52,2 & 8,6 & 52,2 & 0 \\
III & 39,2 & 52,2 & 34,8 & 4,3 \\
IV & 4,3 & 39,2 & 0 & 95,7 \\
\hline
\end{tabular}

Nota: Categoria I: cena e personagens; Categoria II: cena, personagens e situação-problema; Categoria III: cena, personagens, situação-problema e desfecho súbito; e Categoria IV: completa.

FONTE: As autoras. 
No pós-teste, diferenças significativas foram observadas em relação à Categoria III $(U=159,50 ; \mathrm{p}=0,000)$ e à Categoria IV $(U=158,00 ; \mathrm{p}=\mathrm{p}=$ $0,000)$, uma vez que o percentual de histórias na Categoria III era mais alto no Grupo Controle do que no Experimental, enquanto o oposto era observado em relação à Categoria IV. Embora os dois grupos apresentassem o mesmo nível elementar de produção escrita no pré-teste, no pós-teste a quase totalidade das histórias do Grupo Experimental eram completas e elaboradas (Categoria IV).

O Teste de Wilcoxon revelou que no Grupo Controle, histórias classificadas na Categoria II eram mais frequentes no pré-teste do que no pós-teste ( $\mathrm{Z}=$ $-2,953, p=0,002)$ e que as da Categoria IV eram mais observadas no pós-teste do que no pré-teste $(Z=-2,652, \mathrm{p}=0,005)$. No Grupo Experimental, a Categoria II e a Categoria III eram mais produzidas no pré-teste do que no pós-teste ( $Z$ $=-2,731, p=0,005)$, enquanto que a Categoria IV era expressivamente mais observada no pós-teste que no pré-teste $(\mathrm{Z}=-2,952, \mathrm{p}=0,00)$. Embora em ambos os grupos haja progressos da primeira para a segunda testagem, o avanço foi mais expressivo no Grupo Experimental (Tabela 1), visto que após a intervenção, 95,7\% das histórias eram completas e elaboradas (Categoria IV).

Em estudos de intervenção é relevante examinar os casos de regressão (passar de uma categoria mais elaborada para uma menos elaborada), de estabilidade (permanecer na mesma categoria) e de progressão (passar de uma categoria menos elaborada para uma mais elaborada) identificados entre as ocasiões de testagem em um mesmo grupo de participantes. Nenhum caso de regressão foi observado. O Qui-Quadrado revelou diferenças significativas entre os grupos em relação à estabilidade $\left(X^{2}=19,28, \mathrm{p}=0,001\right)$ e à progressão $\left(X^{2}=\right.$ $15,12 ; p=0,001)$. Isso ocorreu porque todas as crianças do Grupo Experimental progrediram, enquanto as do Grupo Controle apresentaram progressão $(59,5 \%)$ e estabilidade (40,5\%).

Para examinar a natureza da progressão, elaborou-se a Tabela 2, observando-se que no Grupo Controle o progresso foi mais tímido (da Categoria II para a Categoria III: 57,2\%) do que no Grupo Experimental (da Categoria II para a Categoria IV: 52,3\%).

Avanços substanciais da Categoria I para a Categoria IV, ainda que raros, ocorreram apenas no Grupo Experimental (13\%). Observa-se, portanto, que entre as crianças que participaram da intervenção houve uma progressão expressiva de histórias incompletas para histórias completas com estrutura narrativa elaborada. 
TABELA 2 - PORCENTAGEM DE HISTÓRIAS QUE PROGREDIRAM DO PRÉTESTE PARA O PÓS-TESTE

\begin{tabular}{ccc}
\hline Natureza da progressão & $\begin{array}{c}\text { Grupo Controle } \\
(\mathbf{n = 1 4 )}\end{array}$ & $\begin{array}{c}\text { Grupo Experimental } \\
(\mathbf{n = 2 3 )}\end{array}$ \\
\hline Categoria I para II & 0 & 0 \\
Categoria I para III & 7,1 & 0 \\
Categoria I para IV & 0 & 13 \\
Categoria II para III & 57,2 & 4,3 \\
Categoria II para IV & 14,3 & 52,3 \\
Categoria III para IV & 21,4 & 30,4 \\
\hline
\end{tabular}

Nota: Categoria I: cena e personagens; Categoria II: cena, personagens e situação-problema; Categoria III: cena, personagens, situação-problema e desfecho súbito; e Categoria IV: completa. FONTE: As autoras.

\section{Os elos de coesão empregados}

O levantamento dos recursos coesivos (1239 ao todo) foi feito por dois juízes cegos e independentes, com $98 \%$ de concordância entre eles, sendo os casos de discordância analisados por um terceiro juiz, cuja classificação concordava sempre com um dos outros juízes.

As referências identificadas foram as pessoais e as demonstrativas, que são elementos que permitem que algo anteriormente apresentado no texto seja retomado (referido), garantindo, assim, sua interpretabilidade. Exemplos: "Era um menino bom, alegre e estudioso. Ele era um menino comportado demais, ele era muito comportado", "Estava numa floresta e pensando em começar a aventura dele".

Conjunções permitem estabelecer diferentes relações entres partes do discurso. As aditivas exprimem acréscimo de informações ("Emili era bonita e educada."); as adversativas designam contraste, oposição entre proposições ("Um belo dia Rodrigo foi tentar voar. Mas ele não sabia voar"); as causais marcam relações entre causa e consequência ou uma explicação/justificativa acerca de algo ("Ele morava numa casa bem rica e por isso que a amiga dele gostava de ir pra casa dele."); as continuativas expressam continuidade entre eventos ("E Marcos lembrou a direção de casa e voltaram pra casa e eles ficaram felizes."); e as temporais expressam duração, simultaneidade e sucessão de eventos ("Quando eles chegaram lá eles viram um fantasma."). 
Como pode ser visto na Tabela 3, o uso de referências e conjunções não diferiu entre os grupos e nem tampouco entre as testagens. No Grupo Controle não houve diferenças quanto ao uso de coesivos nas duas ocasiões de testagem.

TABELA 3 - MÉDIA DE COESIVOS POR HISTÓRIA

\begin{tabular}{ccccc}
\hline & \multicolumn{2}{c}{ Grupo Controle } & \multicolumn{2}{c}{ Grupo Experimental } \\
\hline Coesivos & Pré-teste & Pós-teste & Pré-teste & Pós-teste \\
\hline Referências & 5,6 & 5,3 & 5,3 & 8,6 \\
Conjunções & 6,4 & 6,6 & 6,7 & 9,3 \\
Total & 12,1 & 11,8 & 12 & 17,8 \\
\hline
\end{tabular}

FONTE: As autoras.

No Grupo Experimental, a média de coesivos por história foi significativamente mais alta no pós-teste do que no pré-teste, tanto no geral, como em relação ao uso de referências e conjunções (Teste $T, t=15.296$; $p<0,005$ ). As produções desse grupo no pós-teste eram mais densas do ponto de vista da coesão (média de 17,8 coesivos).

Foi conduzida uma análise das conjunções presentes nas histórias escritas pelas crianças do Grupo Experimental, visto que apenas neste grupo o uso de relações coesivas se alterou do pré-teste para o pós-teste (Tabela 4).

TABELA 4 - PORCENTAGEM DE HISTÓRIAS EM QUE ESTAVAM PRESE
\begin{tabular}{ccc}
\hline \multicolumn{3}{c}{ GS CONJUNÇÕES } \\
\hline Conjunções & Pré-teste & Pós-teste \\
\hline Aditiva & 100 & 100 \\
Continuativa & 86,9 & 100 \\
Temporal & 65,2 & 100 \\
Causal & 46,7 & 60,9 \\
Adversativa & 0 & 34,8 \\
\hline
\end{tabular}

FONTE: As autoras.

As conjunções aditivas e continuativas foram as mais empregadas por ambos os grupos. Por outro lado, conjunções temporais, causais e adversativas eram mais empregadas pelo Grupo Experimental após a intervenção (Teste T, $\mathrm{t}=17.103 ; \mathrm{p}<0,005)$. Após a intervenção, as histórias continham uma maior densidade e variedade de coesivos, incluindo conjunções sofisticadas com as adversativas que estavam ausentes na primeira testagem. 


\section{Conclusões e discussão}

Os dados derivados deste estudo evidenciam que é possível que crianças em anos iniciais do ensino fundamental desenvolvam a habilidade de escrever histórias a partir de conhecimento sobre sua estrutura, organização e convenções linguísticas. Esse conhecimento contribuiu para que crianças que tendiam a produzir histórias incompletas (limitadas à introdução da cena e dos personagens ou com um esboço de uma situação-problema, mas sem um desfecho), após a intervenção passassem a escrever histórias completas e elaboradas. As atividades de natureza metatextual da intervenção levaram as crianças a refletir sobre a estrutura do texto (GOMBERT, 1992; SPINILLO, 2009) e aplicá-la às suas produções escritas, contribuindo para o uso de recursos coesivos variados e apropriados.

Importante comentar que o efeito da intervenção sobre o uso de coesivos é indireto, sendo mediado pela qualidade narrativa das produções. Nas histórias mais elaboradas (com uma situação-problema e desfecho) os episódios se articulavam por meio de coesivos. Este resultado corrobora o que foi observado por Spinillo (1996) e por Fayol e Mouchon (1997) acerca da relação entre o domínio de um esquema narrativo e o uso de elos coesivos, tanto em histórias produzidas na modalidade oral como na escrita.

Colocando em perspectiva os resultados de Ferreira e Spinillo (2003) e aqueles obtidos neste estudo, conclui-se que o conhecimento sobre as propriedades estruturais de histórias propicia tanto a produção tanto oral como escrita de textos. Possivelmente, os aspectos macrolinguísticos (organização e partes constituintes) são conhecimentos de amplo espectro que atuam como um esquema que se aplica às produções em ambas as modalidades. Os dados apontam para a existência de relações entre consciência metatextual e produção textual, de modo que a tomada de consciência acerca da estrutura do texto surge como um dos conhecimentos necessários para produzir textos elaborados.

Entretanto, torna-se ainda necessário aprofundar o conhecimento sobre as relações entre consciência metatextual e escrita de textos de diferentes tipos, pois a configuração dessas relações pode variar de um texto para outro. Se quanto a textos narrativos e expositivos essa relação parece ser clara, o mesmo não ocorre no que se refere à escrita de textos argumentativos, como documentam Pinheiro e Leitão (2007).

Implicações educacionais podem ser consideradas, no sentido de promover situações didáticas baseadas em um tratamento linguístico do texto que permita refletir acerca de suas propriedades, como realizado na intervenção descrita 
nesta pesquisa que pode ser adaptada ao contexto de sala de aula. É necessário, e possível, portanto, desenvolver desde cedo habilidades que estimulem os alunos a usar a escrita de forma ampla, indo além do domínio do código alfabético, das regras ortográficas e gramaticais, de modo que venham a escrever textos coesos e com uma estrutura elaborada.

\section{REFERÊNCIAS}

ENGLERT, C. S.; STEWART, S.; HIEBERT, E. Young writers' use of text structure in expository text generation. Journal of Educational Psychology, 80(2), 143-151, 1988.

FAYOL, M. Stories: a psycholinguistic and ontogenetic approach to the acquisition of narrative abilities. In: PIERÁULT-LE BONNIEC, G.; DOLITSKY, M. (Org.). From basic language to discourse basis processing. Amsterdam: Benjamin, 1991. p. 229-243.

FAYOL, M.; MOUCHON, S. Production and comprehension of connectives in the written modality: a study of written French. In: PONTECORVO, C. Writing development: an interdisciplinary view. Philadelphia: John Benjamins, 1997. p. 193-204.

FITZGERALD, J.; TEASLEY, A. Effects of instruction in narrative structure on children's writing. Journal of Educational Psychology, 78(6), 424-432, 1986.

FERREIRA, A.; SPINILLO, A. G. Desenvolvendo a habilidade de produção de textos em crianças a partir da consciência metatextual. In: MALUF, M. R. (Org.), Metalinguagem e aquisição da escrita: contribuições da pesquisa para a prática da alfabetização. São Paulo: Casa do Psicólogo, 2003. p. 119-148.

GOMBERT, J. Metalinguistic Development. Harvester: Wheatsheaf, 1992

LINS E SILVA, M. E.; SPINILLO, A. G. A influência de diferentes situações de produção na escrita de histórias. Psicologia: Reflexão e Crítica, 13(3), 337-350, 2000.

MARCUSCHI, L. A. Produção textual, análise de gêneros e compreensão. São Paulo: Parábola Editorial, 2008.

PESSOA, A. P.; CORREA, J.; SPINILLO, A. G. Contexto de produção e o estabelecimento da coerência na escrita de histórias por crianças. Psicologia: Reflexão e Crítica, 23(2), 253-260, 2010.

PINHEIRO, F.; BECKER, M. L. A coerência em narrativas escritas escolares: uma análise piagetiana. Educar em Revista, 53(3), 217-231, 2014.

PINHEIRO, R.; LEITÃO, S. Consciência da "estrutura argumentativa" e produção textual. Psicologia: Teoria e Pesquisa, 23(4), 423-432, 2007. 
PONTECORVO, C.; ORSOLINI, M.; RESNICK, L. Introduction. In: PONTECORVO, C.; ORSOLINI, M.; BURGE, B.; RESNICK, L. (Org.). Children's early text construction. Mahwah, NJ.: Lawrence Erlbaum, 1996. p. x-xvi.

REGO, L. L. B. A escrita de estórias por crianças: as implicações pedagógicas do uso de um registro linguístico. Revista de Documentação de Estudos em Linguística Teórica e Aplicada (DELTA), 2(2), 165-180, 1986.

REYNOLDS, G.; PERIN, D. A comparison of text structure and self-regulated writing strategies for composing from sources by middle school students. Reading Psychology, 30(3), 265-300, 2009.

SINGER, B.; BASHIR, A. Developmental variations in writing composition skills. In: STONE, A.; SILLIMAN, E.; EHREN, B.; APEL, K. (Org.). Handbook of language and literacy: development and disorders. New York: The Guilford Press, 2004. p. 559-582.

SPINILLO, A. G. O uso de coesivos por crianças com diferentes níveis de domínio de um esquema narrativo. In: DIAS, M. da G.; SPINILLO, A. G. (Org.). Tópicos em Psicologia Cognitiva. Recife: Editora da UFPE, 1996. p. 84-119.

SPINILLO, A. G. A consciência metatextual. In: MOTA, M. (Org.). Desenvolvimento metalinguístico: questões contemporâneas. São Paulo: Casa do Psicólogo, 2009. p. 77-113.

TAYLOR, B.; BEACH, R. The effects of text structure instruction on middle-grade students' comprehension and production of expository text. Reading Research Quarterly, 19(2), 134-146, 1984.

Texto recebido em 19 de agosto de 2017. Texto aprovado em 23 de janeiro de 2018. 
